\section{SIX CASES OF EXCISION OF THE LARYNX.}

BY F. G. HARVEY, F.R.O.S. EDIN.,

SURGEON TO THE HOSPITAL FOR DISEASES OF THE THROAT', GOLDEN SQUARE, W.C.

As the recorded cases of complete excision of the larynx are comparatively few, and the details of the method, as far as I know, have not been fully described, I think it may be of interest to publish these cases.

The complete removal of the larynx by the method which aims at cutting the trachea and lungs off completely from the pharyngeal cavity, and obtaining primary union of the parts divided when severing the larynx from its connexions, was, I believe, first described by Rötter, and to him I am mainly indebted. I have not seen his paper, but' merely an abstract of it, and I propose now to offer somewhat fuller details of the method, in the hope that it may be of use to those who have not seen the operation or to those who, like myself, have seen no detailed account. I shall follow in the main Rötter's description. I claim no originality, but shall speak a little in detail on some points which have appeared to me to offer practical difficulty.

The operation may be performed by separating the trachea and cricoid cartilage from the osophagus, commencing from above and working downwards or commencing from below and working upwards. I will describe the latter method. I assume the proper preparation of the patient for a long and serious operation, strict antiseptic precautions, and the proper warming and ventilation of the operating room, with as little exposure of the body as possible.

The first step, after administering chloroform to the patient, is to make a vertical incision extending from the hyoid bone to a point as low as the fourth or fifth ring of the trachea. A transverse cut should be made along the whole length of the under surface of the hyoid bone through skin and fascia, dividing the anterior jugular veins which must be tied. The sterno-hyoid, the omo-hyoid, and the thyro-hyoid muscles are divided at their insertion into the hyoid close to the bone, and the flaps thus formed are reflected downwards and outwards to either side. The thyroid isthmus should then be divided between two ligatures and the lobes of the thyroid separated from the trachea. When the trachea is completely bared it may be divided from before backwards and the lower portion separated from its attachments to the cesophagus and stitched to the skin. A Hahn's cannula will now be introduced, all bleeding will be arrested, and the parts immediately around the lower portion of the severed trachea will be packed with gauze. It will be found necessary to remove the Hahn's cannula from time to time and to clear the trachea of any blood which may have found its way into. it. The patient at this point must not be deeply under the influence of the chloroform, as we shall then have warning of any blood trickling into the lungs by his coughing; if this occurs it will be well to sponge out the trachea by introducing for some distance a swab or sponge on a holder. The next step will be to dissect off the upper portion of the trachea from the osophagus and the muscles from the lateral surface of the cricoid. The inferior cornu of the thyroid is next bared by detaching and reflecting the crico-thyroid and inferior constrictor muscles. The muscles and perichondrium in front of the thyroid will now be separated and reflected as far back as the superior cornu, which latter will next be freed by dividing the periosteum on its surface, and pushing it along with the lateral wall of the pharynx and the loose areolar tissue backwards until the posterior lateral border of the cricoid is reached. The outer two-thirds of the lateral portion of the thyro-hyoid membrane, which is attached to the superior border of the thyroid cartilage, will then be divided transversely and cautiously at the point of junction of its upper and middle thirds; and when the adjacent mucous membrane is reacher this must be picked up with forceps and divided, whereby the upper portion of the epiglottis can be seized and drawn forwards. The anterior wall of the pharynx is thus opened, and by pulling the epiglottis strongly forward and with it the whole larynx the knife can be placed on the posterior surface of the cricoid, and by cutting downwards the anterior wall of the œsophagus will be opened. Care must be taken at this point to limit the cut to the parts which are covered in front by the posterior surface of the cricoid; if this is not done the lateral wall of the pharynx and the osophagus will be unnecessarily encroached upon and too much of their anterior walls will be removed, thus rendering it difficult to approximate their edges. The whole larynx is thus com. pletely detached, and the defect in the pharyngeal mucous membrane must now be made good by inserting sutures quite close to the cut edges and so preventing in-turning of the epithelial surfaces. The sewing up must be watertight with fine catgut sutures so as to form a Y-shaped stitched line, then a row of Lembert's sutures must be added transfixing the muscular and cellular coats of the cesophagus and pharynx. The third layer nnites the stumps of the pharyngeal constrictors, and the fourth layer brings together the divided sterno-hyoid and thyrohyoid muscles. Finally the $T$-shaped skin incision will be united, leaving only a three-cornered cavity above, which may be packed with iodoform gauze; thus, only the above cavity and the tracheotomy will remain unclosed. The Hann's cannula may be removed in 24 hours. Nutriment will be administered by the rectum for from 24 to 48 hours, after which milk may be given by the mouth. Rötter suggests that the trachea should be divided from behind forwards, but it is far more easy, expeditious, and safe to divide it as I have described. I need hardly emphasise the importance of keeping blood out of the lungs, the whole success turning on this point and the accurate suturing of the pharyin and oesophagus. Of the six cases here noted it will be seen that three were treated by this method. Of the remaining three, one was treated by the older method with a preliminary tracheotomy and stitching the pharynx to the skin ; the second can hardly be classed as an excision, inasmuch as the whole of the larynx, when the soft parts covering it were reflected, was capable of being lifted off.

CASE 1.-A man, aged 49 years, came to the Hospital for Diseases of the Throat on July 17th, 1894 . He had been a patient 12 months previously and he was then advised to have his larynx removed but would not consent. When he was admitted on the second occasion the disease was thought to be too far advanced for operative interference and it was only at his urgent solicitation that $I$ consented to make the attempt, after having explained to him that I did not hold out any hope of success. The diagnosis, which was veriffed br subsequent examination, was that of squamous epithelioma, and the prognosis was one of early asphyzia if the patient were unrelieved by tracheotomy. The method of operating was as follow's. A preliminary low tracheotomy was performed some fortnight before the major operation, which latter was done on August 14th. Chloroform was first administered and then the tracheotomy tube was removed and the wound was slightly enlarged. A Hahn's cannula was inserted into the trachea, an incision was made down the front of the neck from the hyoid level to the upper part of the tracheotomy wound, and another incision was made transversely along the under surface of the hyoid bone. The tissues were then dissected off the thyroid and cricoid cartilages. There was a small piece of growth coming through the crico-thyroid membrane. The larynx was removed, leaving a portion of the left thyroid cartilage; the edges of the mucous membrane were stitched to the skin and the transverse incision was closed by sutures. Bleeding was slight and the patient bore the operation well. A soft rubber feeding-tube was put in the oesophagus and fixed. With regard to the after-history the general condition remained good after the operation, the temperature ranging between $98.8^{\circ}$ and $99.6^{\circ} \mathrm{F}$., the pulse and respiration being about 80 and 19 respectively. A plastic operation was subsequently undertaken to cure the opening in the gullet. The patient has since remained in excellent health, carrying on his duties uninterruptedly, and when seen a few weeks ago his condition was in every way satisfactory. $\mathrm{He}$ has an artificial lairynx whereby he can speak quite well by closing with his finger the outer opening of the tracheal tube.

CASE 2.-The patient was a female, aged 29 years. The diagnosis was that of carcinoma of the larynx. The prognosis was one of early asphyxia if the patient were unrelieved by tracheotomy. The operation was performed on August 22nd, 1894, the method adopted being as follows. A vertical incision in the middle line of the neck from the hyoid to just above the sternal notch and a horizontal incision along the lower border of the hyoid bone were made the flaps thus formed were reflected downwards and 
npwards, together with the whole of the soft structures covering the front of the larynx. When this was done it was found that the whole of the cartilages of the larynx were so thinned and brittle that the larynx did not admit of being removed in its entirety, but crumbled away piecemeal, even on gentle manipulation. When thus removed it was found that the disease had involved, and in a great mousure destroyed, the anterior wall of the pharynx and upper portion of the cesophagus. No vestige of the larynx remained and it was not possible to restore any part of the pharynx by suturing. It was with difficulty that the distal end of the œsophagus was reacher and secured to the edges of the wound above and behind the trachea. A tracheotomy tube was placed in the trachea at a rather lower level. With regard to the after-history the patient remained in the hospital for several months and was then transferred to the cancer wards of the Middlesex Hospital, where I nnderstand that after a sojourn of some wceks she ricd, the immediate cause being hemorrhage in the vicinity of the wound.

CASE 3. - The patient was a man, aged 64 years. Carcinoma of the larynx was diagnosed. A few days prior to the operation a tracheotomy had to be hurriedly jerformed owing to a sudden attack of dyspnoca. At the operation, which was done on August 22nd, 1895, a Hahn's cannula was inserted, the thyroud cartilage was split in the midlle line, and the growth was found to be localised to the right side. The right half of the larynx was entirely removed. The operation presented no difficulty. With regard to the after-history the patient progresser favourably until the 29th, when during the morning he was somewhat restless. In the evening of the same day, whilst sitting up and without any premonitory symptoms, his breathing. became embarrassed, he quickly lost consciousness and died in a few minutes. No post-mortem examination was allowerl, and I am quite unable to account for his death, as up to the moming of the day he died no untoward symptoms had manifested themselves.

CASE 4.-The patient was a man. aged 52 rears. $\mathrm{He}$ was a stont but flabby man who had indulged somewhat freely in alcohol. He consulted me in July. 1896. He was then suffering from hoarseness, but his breathing at this time was free. As regards laryngoscopic appearances the right ventricular band was much swollen and there was an ulcer on the posterior part of the right vocal cord. A portion of the growth was removed and was found to be malignant. A few lays later his breathing became embarrassed, necessitating tracheotomy. As the growth was so extensive $I$ advised him to have the larynx removed, but to this he would not consent, though not averse to a thrrotomy. On August 13th the larynx was split and an extensive growth on both sides was found. The ventricular band and nearly the whole of the mucous membrane were removed, the crico-thyroid membrane was divided, and pure carbolic acid was applied, especially to the lower angle of the right ala and cricoid. The patient made a good recovery. I saw him again in October, when there was a large fungating mass projecting from the interior of the larynx and involving the tracheotomy wound. Nothing short of complete excision offered any chance of recovery, so I proceeded on Oct. 22nd to remove the larynx, commencing from above downwards and finally severing the trachea below the insertion of the tracheotony tube. The skin and muscles some inch and a half around the tracheotomy wound were completely cut away and the cervical glands were removed from the sheath of the jugular vein in the lower part of the neck. He made an uninterrupted recovery, taking milk by the mouth in 36 hours. Six weeks later it was found necessary to remove another gland on the opposite side of the neck. In January, 1897, there was a recurrence of the growth in the neck involving the sterno-mastoid muscle on the right which was deemed too extensive for removal. The patient gradually sank and died from asthenia, the growth having involved the neck and thorax ; but the trachea remained free and there was no Ayspncea. 'This case appeared to be of an unusually malignant nature, and it is much to be regretted that the patient did not submit in the first instance to a complete excision of the parts.

OASE 5.-'The patient was a man, aged 61 years. Tracheotomy was performer in May, 1897, for the relief of dyspnca. On Oct. 8th he was found to be almost voiceless and mable to rest at night nwing to freguent blocking of the tube with thick and blowl-stained phlegm. The laryngoscovic appearan'es were an follows. There was a large

swelling on the left side of the epiglottis. The ary-epiglottic fold, ventricular band, and adjoining parts were involved in the infiltration. There were marked irregular isolated nodules on the eviolottis, the right arptenoid was red and swollen, the pharynx appeared free to sight and touch, and the glosso-(piglottidean fold was free. One gland was enlarged above the hyoid bone on the left side. At the oneration, on the.12th, the growth was found to have perforated the cricothyroid membrane on the left side and the sterno-hyoic muscle was found to be infiltrated as far up as the hyoirl. 'I'he cxci-ion was commenced from the upper end and the tracheotony wound was not interfered with until the final severance of the laryns from its conmexions. 'The piece of the hyoid to which the muscle was attached was cut away with bone forceps. The wound was dresserl with boric lint kept constantly wet. At the expiration of 24 hours the patient was able to take milk by the month. On the 23rd there was a slight leakage of milk through the wound. It was cleemed advisable to give all food through an cesophageal tube for a lew days and to plug the wound. He then resumed taking food by the mouth and made an mintersupted recuvery. As reards his after-history, he oained some 2 stones in weight and remained in excellent health for a twelvemonth when he harl an attack of acite pnemmonia and died in a few days. There was no sign of any recurrence of the disease.

CASE 6. - The patient was a man, aged 48 years. On admission to the hospital he was seen to be a big man but not in good condition The heart was slightly enlarged, the pulse was regular, the lungs had moist sounds at their bases, and the liver was not enlarged. The urine was acirl, its pecific gravity being 1030 , with no albumin or: sugar. Ife could only take fluids, but had no pain. As reuards the larynooscopic appearances there was a sessile growth of the size of a large bean situated on an infiltrated base just below the right aryteno-epiglottidean fold and running obliquely down over the ventricular band and liding the anterior two-thirds of the rocal cord. 'The right sicle of the larynx was fixed and the posterior third of the vocal cord, which alone was visible, was seen to be motionless and white. The left side of the larynx and the vocal corl moved freely. A piece of the growth was removed and examined microscopically, the diagnosis of epithelioma being confirmed. There was.an indefinite thickening on the right side of the neck opposite the level of the thyroin cartilage (?enlarged gland). The respiration was comfortable, although there did not seem to be very much room. The voice was hoarse. The history was that until six months before his admission to the hospital the patient had never had any trouble with the throat. About that time he had a little difficulty in swallowing, and a feeling of gurgling in the throat. About two months before the operation he had pneumonia, the temperature reaching $105^{\circ} \mathrm{F}$.. and he suffered from great dyspncea, so much so that tracheotomy was contemplated. During the next two months he was hoarse on and off, gradually getting worse, and there was increased difficulty in swallowing; the cough was often severe, with much phlegm in the throat and occasional slight earache. He could swallow solids until two days before his admission. He had been a heavy smoker and also drank freely, hall suffered from winter congh, and there had been lately some wasting. There was a specific history 25 years before. He had been taking iodide of potassium without any benefit. On July 28th, 1900, I excised the larynx and then found that on the right side at the level of the inferior cornu of the thyroid the growth had perforated into the neck through the posterior part of the crico-thyroid membrane. As regards the afterhistory his health was good and his condition satisfactory up to the following December, when he presented himself for examination. An enlarged gland was found and removed from the sheath of the jugular vein above the level of the great cornu of the hyoid bone on the right side. $\mathrm{He}$ has now a Gluck's artificial larynx, whereby a loud whisper can be produced and conversation can be carried on, and his health appears to be quite satisfactory.

Cavendish-place, W.

Porsoning By Carbolic Acid.-At Redditch on Sept. 11th a man was accidentally poisoned by carbolic acid being given to him instead of some medicine which he was taking for a cold. Death took place in 20 minutes, before medical assistance could be obtained. The carboljc acid was: intenrled to be used for inhalation and was kert with the melicine. 